EVS26

Los Angeles, California, May 6-9, 2012

\title{
A First Look at the Impact of Electric Vehicle Charging on the Electric Grid in The EV Project
}

\author{
Stephen Schey ${ }^{1}$, Don Scoffield ${ }^{2}$, John Smart ${ }^{2}$ \\ ${ }^{I}$ ECOtality North America, 430 S. 2nd Ave., Phoenix, AZ 85003, sschey@ecotality.com \\ ${ }^{2}$ Idaho National Laboratory, 2351.N Boulevard, Idaho Falls, ID 83415, don.scoffield@inl.gov, john.smart@inl.gov
}

\begin{abstract}
ECOtality was awarded a grant from the U.S. Department of Energy to lead a large-scale electric vehicle charging infrastructure demonstration, called The EV Project. ECOtality has partnered with Nissan North America, General Motors, the Idaho National Laboratory, and others to deploy and collect data from over 5,000 Nissan LEAFs ${ }^{\mathrm{TM}}$ and Chevrolet Volts and over 10,000 charging systems in 18 regions across the United States. This paper summarizes usage of residential charging units in The EV Project, based on data collected through the end of 2011. This information is provided to help analysts assess the impact on the electric grid of early adopter charging of grid-connected electric drive vehicles.
\end{abstract}

A method of data aggregation was developed to summarize charging unit usage by the means of two metrics: charging availability and charging demand. Charging availability is plotted to show the percentage of charging units connected to a vehicle over time. Charging demand is plotted to show charging demand on the electric gird over time.

Charging availability for residential charging units is similar in each EV Project region. It is low during the day, steadily increases in evening, and remains high at night. Charging demand, however, varies by region. Two EV Project regions were examined to identify regional differences. In Nashville, where EV Project participants do not have time-of-use electricity rates, demand increases each evening as charging availability increases, starting at about 16:00. Demand peaks in the 20:00 hour on weekdays. In San Francisco, where the majority of EV Project participants have the option of choosing a time-of-use rate plan from their electric utility, demand spikes at 00:00. This coincides with the beginning of the off-peak electricity rate period. Demand peaks at 01:00.

Keywords: BEV (battery electric vehicle), demonstration, infrastructure

\section{Introduction}

Concerns with global climate change, United States reliance on foreign oil, increasing global demand for petroleum-based fuels, and increasing gas prices are changing consumer preferences and industry direction toward more fuel-efficient and alternative energy vehicles. Nissan and General Motors have successfully introduced a new generation of plug-in electric vehicles (PEV). 
Several other automotive manufacturers plan to launch PEVs in 2012. This illustrates a shift to cleaner and more efficient electric drive systems. These vehicles, which include plug-in hybrid electric vehicles, extended range electric vehicles, and battery electric vehicles draw some or all of their motive power from onboard batteries, which are charged from the electric grid. In order for PEVs to be commercialized, electric charging infrastructure must be deployed. Charging infrastructure must be safe, financially viable, and convenient. Additionally, electric utilities must be able to manage PEV charging demand on the electric grid.

For years, researchers have worked to model future PEV and charging infrastructure markets to assess the impact of charging PEVs on the electric grid [1-3]. Small-scale demonstrations have been conducted to document actual PEV charging behavior and grid impact using aftermarket conversion PEVs [4]. With the recent launch of high-volume PEVs by major automakers, it is now possible to deploy charging infrastructure and assess grid impact with large-scale demonstrations.

In 2009, ECOtality was awarded a grant from the U.S. Department of Energy to embark on such a demonstration, called The EV Project. With matching cost share from ECOtality and its partners, The EV Project's total project budget is approximately $\$ 230$ million. ECOtality is partnering with Nissan North America, General Motors, and several other companies to deploy over 5,000 Nissan LEAF $^{\mathrm{TM}}$ battery electric vehicles and Chevrolet Volts extended range electric vehicles and over 10,000 charging systems to support them. These charging systems, referred to as electric vehicle supply equipment (EVSE), are being installed in private and public locations in 18 strategic markets across the United States.

The purpose of this paper is to summarize early EV Project residential EVSE usage and demand on the electric grid, based on data collected through the end of 2011. This information is provided to help analysts assess the impact of early adopter PEV charging on the electric grid.

\subsection{Project Description}

The purposes of The EV Project are to characterize vehicle and EVSE usage in diverse topographic and climatic conditions, evaluate the effectiveness of charging infrastructure, and conduct trials of various revenue systems for commercial and public charging infrastructure. The ultimate goal of The EV Project is to take the lessons learned from the deployment of these first PEVs and the charging infrastructure supporting them to enable the streamlined deployment of the next five million PEVs. To accomplish these purposes, ECOtality has partnered with the Idaho National Laboratory to collect and analyze electronic data from EV Project vehicles and charging units.

The EV Project uses the Blink brand of EVSE, which is manufactured by ECOtality. The Blink product line consists of AC Level 2 residential and commercial EVSE and a DC Level 2 commercial fast charger. The AC Level 2 EVSEs are 240-VAC, single-phase units, operating at charge rates up to $7.2 \mathrm{~kW}$. Blink EVSE are networked, enabling data collection, user authentication, and additional functionality. All units have internal energy meters and touchscreen user interfaces and allow user-controlled charge scheduling. Numerous data parameters are collected from the Blink EVSE participating in The EV Project, including time when the EVSE is connected to a vehicle and transferring power to the vehicle, energy consumed from the grid, and 15-minute rolling average power demand.

Vehicles enrolled in The EV Project include the Nissan LEAF and the Chevrolet Volt. Both vehicles connect to AC Level 2 EVSE using SAE J1772@-compliant connectors. Figure 1 shows a Volt connected to a Blink AC Level 2 commercial EVSE unit.

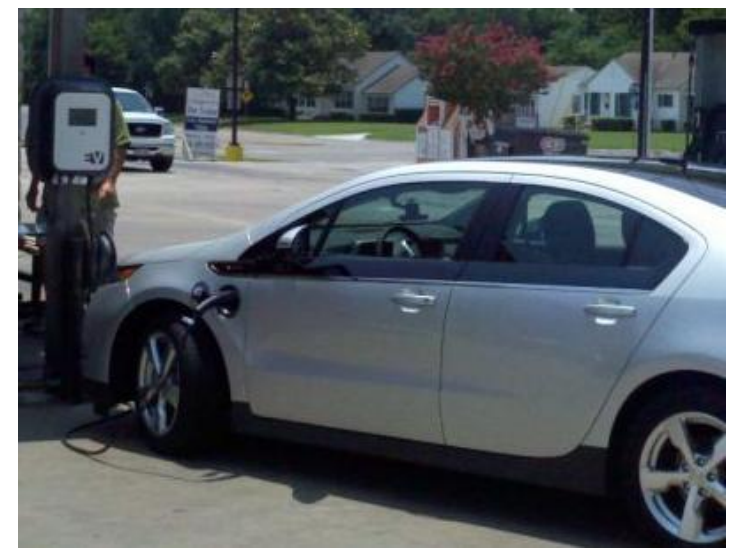

Figure 1: Blink AC Level 2 with Chevrolet Volt. 
Table1: Number of EV Project EVSE and vehicles, by region, from which data was collected in 2011.

\begin{tabular}{l|c|c|}
\cline { 2 - 3 } EV Project Region & $\begin{array}{c}\text { Number of } \\
\text { Vehicles } \\
\text { Enrolled }\end{array}$ & $\begin{array}{c}\text { Number of } \\
\text { EVSE } \\
\text { Installed }\end{array}$ \\
\hline Phoenix, AZ & 210 & 254 \\
\hline Tucson, AZ & 64 & 78 \\
\hline Los Angeles, CA & 384 & 311 \\
\hline San Diego, CA & 622 & 606 \\
\hline San Francisco, CA & 1,044 & 869 \\
\hline Washington, D.C. & 45 & 2 \\
\hline Oregon & 365 & 429 \\
\hline Chattanooga, TN & 34 & 58 \\
\hline Knoxville, TN & 67 & 105 \\
\hline Memphis, TN & 21 & 18 \\
\hline Nashville, TN & 289 & 335 \\
\hline Dallas/Ft. Worth, TX & 52 & 40 \\
\hline Houston, TX & 43 & 22 \\
\hline Washington State & 607 & 658 \\
\hline Total & 3,847 & 3,785 \\
\cline { 3 - 3 } & &
\end{tabular}

Additionally, both the LEAF and Volt are capable of charging at any standard 120-volt outlet, using the AC Level 1 cordset supplied by the manufacturer. Nissan LEAFs in The EV Project also accept DC fast charging. Figure 2 shows a Nissan LEAF connected to a Blink DC fast charger. Both the LEAF and Volt have user interfaces allowing drivers to set charge schedule preferences.

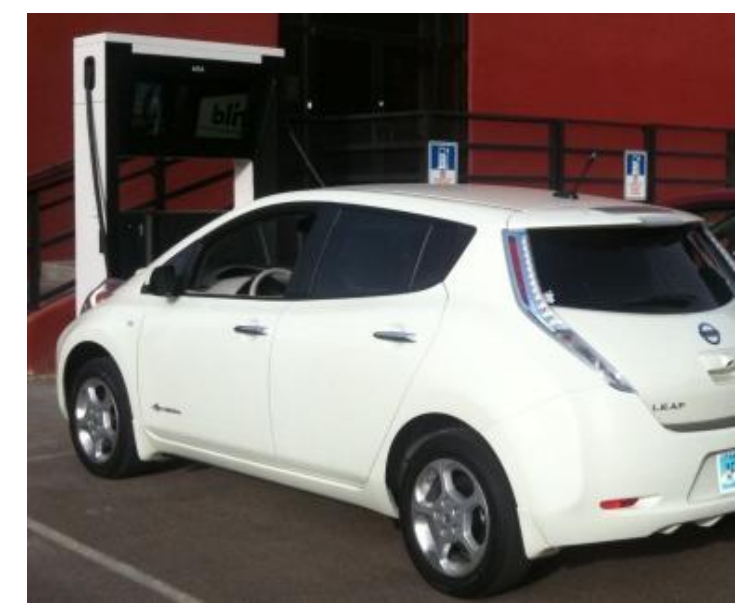

Figure 2: Blink DC fast charger with Nissan LEAF.

Figure 3 shows the major metropolitan areas where The EV Project is deploying charging infrastructure.

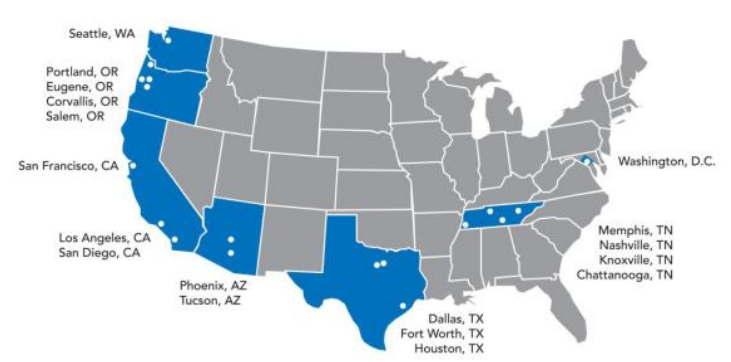

Figure 3: EV Project cities.

At the end of 2011, there were approximately 4,000 Nissan LEAFs and 200 Chevrolet Volts enrolled in the project. There were equal numbers of residential EVSE installed, because each participating vehicle owner had a Blink residential AC Level 2 EVSE installed in their residence. Additionally, approximately 950 publicly available AC Level 2 EVSE and 15 DC fast chargers had been installed by the end of 2011 . Table 1 shows the number of units, by project region, that had been deployed and transferred data to the Idaho National Laboratory.

The EV Project's deployment phase will continue through 2012, during which time additional vehicles and EVSE will be enrolled in the project. Data collection will continue for 1 year following completion of the deployment phase.

While still early in the project at the time of this writing, the number of vehicles and EVSE enrolled is significant. This allows a preliminary assessment of the impacts of these PEVs on the grid. This paper focuses on the usage of residential EVSE in households with Nissan LEAFs and their aggregate electricity demand relative to time of day and day of the week. Additional studies will be conducted as The EV Project progresses to include the effect of nonresidential charging, including DC fast charging and localized distribution of EVSE on the electric grid.

\section{Data Aggregation Approach}

It is useful to understand how EVSEs are being utilized through time. Specifically, knowing when vehicles are connected to the grid and when power is being drawn from the grid is valuable information. In order to communicate this information, two curves were calculated from EV Project EVSE usage data: the charging availability curve and charging demand curve. These curves and the associated plots are described below. 


\subsection{Charging Availability}

Charging availability at a point in time is the percentage of EVSE in a geographical area that are connected to a vehicle. The charging availability curve depicts the charging availability on a 15-minute interval versus time. The charging availability curve is a good way to observe the collective behavior of a large sample of vehicle owners as they connect and disconnect their PEVs to and from their EVSE. Figure 4 shows the charging availability curve for a 3-week time period during October 2011 for many residential EVSE in The EV Project.

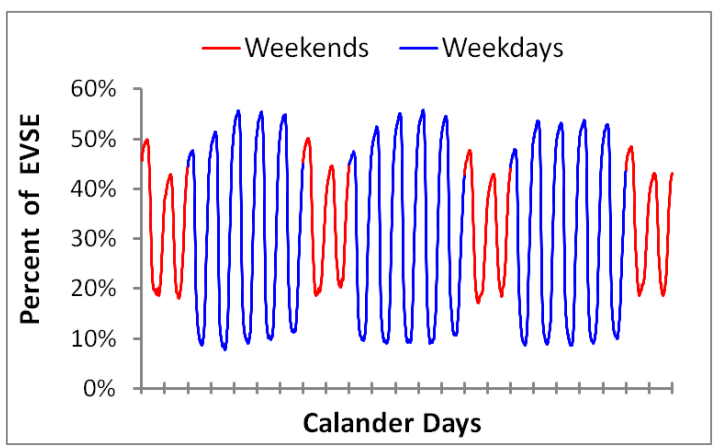

Figure 4: Charging availability curve for many residential EVSE in The EV Project.

The charging availability curve for residential EVSE is a periodic curve with both daily and weekly patterns. The daily peaks and troughs of the curve correspond to the night time and day time, respectively. The peaks are caused as people return to their residences and plug in their vehicles in the evening. The troughs are caused as people unplug their vehicles and (presumably) leave their residences. The weekly pattern revolves around the weekends. The weekend days tend to have lower peaks and higher troughs than the weekdays. Higher troughs during the day result from fewer people unplugging their vehicles on weekend days. Lower peaks are due to the fact that fewer EVSE, which had been disconnected, were connected in the evening.

The daily and weekly patterns in the charging availability curve can be displayed using a 24-hour time-of-day plot for weekdays and another 24-hour time-of-day plot for weekend days. This kind of time-of-day plot is a concise way to visualize the daily behavior of many calendar days of data simultaneously. To create a time-of-day plot, the charging availability curves for each calendar day are superimposed on the same 24-hour scale. Figure 5 shows this superposition of each day in the weekday charging availability curve depicted in Figure 4.
To reduce the noise caused by the individual calendar day curves, the area between the maximum and minimum curves at each point in time are filled in. This creates an envelope of charging availability (as shown in Figure 6). The maximum and minimum charging availability at each point in time across all calendar days is highlighted with blue and green lines, respectively.

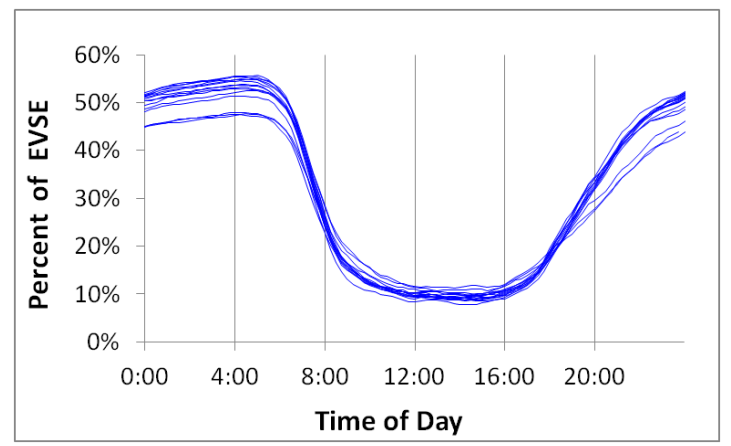

Figure 5: Weekday time-of-day charging availability from Figure 4 plotted on a single 24-hour scale.

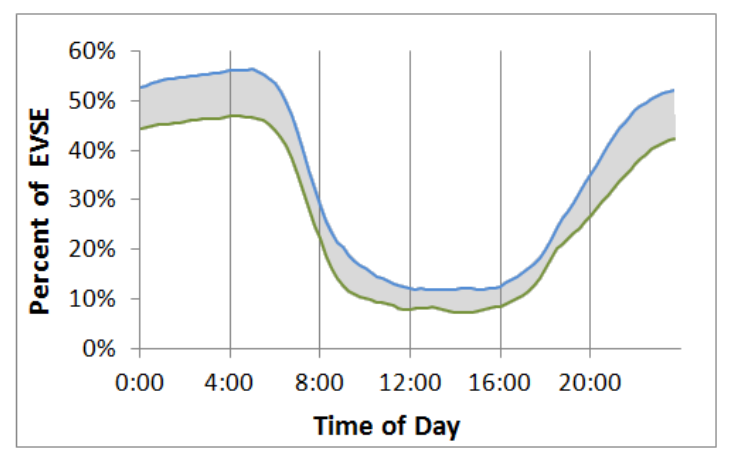

Figure 6: Weekday time-of-day charging availability envelope derived from Figure 5.

\subsection{Charging Demand}

Charging demand at a point in time is the total amount of power being drawn from the electric grid by a group of EVSE in a geographical area. This is typically shown as a curve of charging demand versus time, which is sometimes referred to as a load profile. Figure 7 shows the charging demand curve during a 3-week time period for many residential EVSE in The EV Project. This curve is based on 15-minute rolling average power measurements collected from the EVSE.

The charging demand curve is a periodic curve, with both daily and weekly patterns similar to the charging availability curve. The daily peaks and troughs of the charging demand curve correspond to the night time and day time, respectively. The demand at night is high, whereas the demand 
during the day is close to zero. This indicates a strong preference among EV Project participants for night-time residential charging. The weekly pattern revolves around the weekends. The lowest demand occurs on the weekend days. Demand increases on each weekday until it reaches a peak on Wednesday or Thursday night. Then demand diminishes again as the weekend comes.

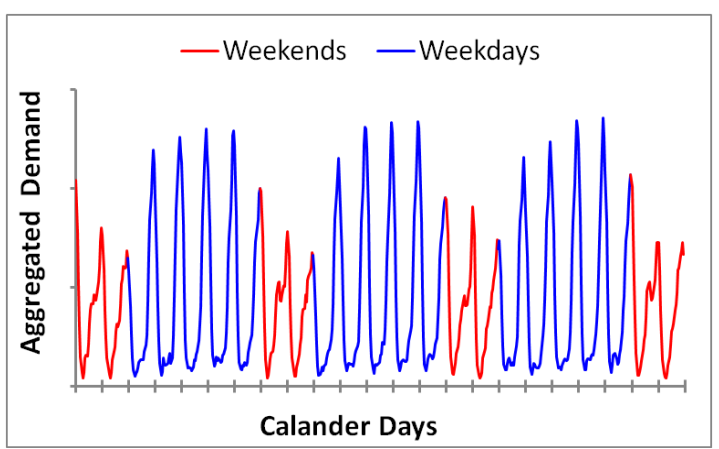

Figure 7: Charging demand curve for many residential EVSE in The EV Project.

Because the charging demand curve follows the same periodic patterns as the charging availability curve, weekday and weekend time-of-day plots also will be used to visualize the charging demand.

\subsection{Time-of-Day Plot Variations}

Additional information beyond the maximum and minimum curves can be added to a time-of-day plot. Two variations of the time-of-day plots are described below.

\section{Peak Day}

In the time-of-day demand plot, it is sometimes helpful to visualize charging demand for one calendar day. While any calendar day could be chosen, it was decided to show the demand for the "peak day" in some reports for The EV Project [5]. The peak day is defined as the calendar day during the time period being analyzed, on which day the highest demand was experienced. For example, the highest weekday charging demand during the 3-week period in October analyzed above occurred at 23:00 on October 13, 2011. Therefore, the charging demand curve for the entire day of October 13 is shown as the peak day curve on the time-of-day charging demand plot. The time-of-day charging availability plot shows the charging availability curve for October 13 , as well. Figures 8 and 9 show the peak day curves on these two plots.

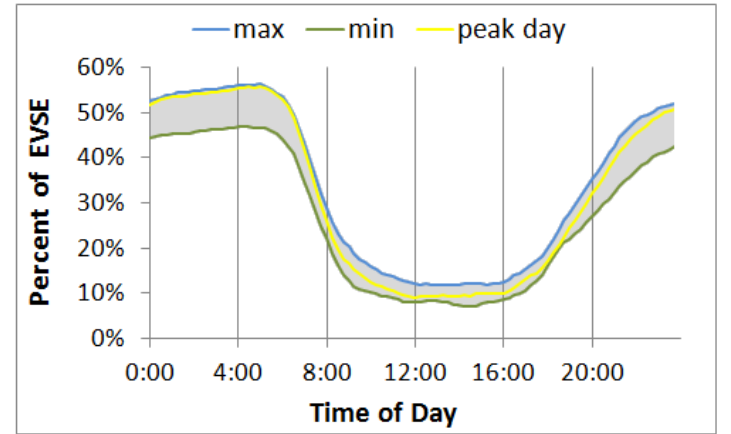

Figure 8: Time-of-day charging availability plot with peak day curve.

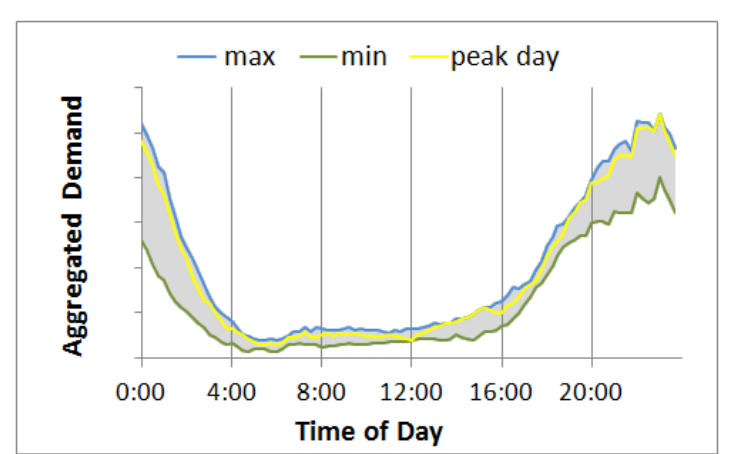

Figure 9: Time-of-day demand plot with peak day curve.

\section{Quartiles}

In a time-of-day plot, it also is helpful to see how the data points from each calendar day are distributed between the maximum and minimum at any time of day. This is depicted by dividing the range between the maximum and the minimum into quartiles and displaying the median and the inner quartile range (IQR). The median is a measure of central tendency that corresponds to the $50^{\text {th }}$ percentile. The IQR is the range between the $25^{\text {th }}$ to the $75^{\text {th }}$ percentiles. It is used as a measure of the spread of the data. Time-of-day plots with these features are shown in Figures 10 and 11 .

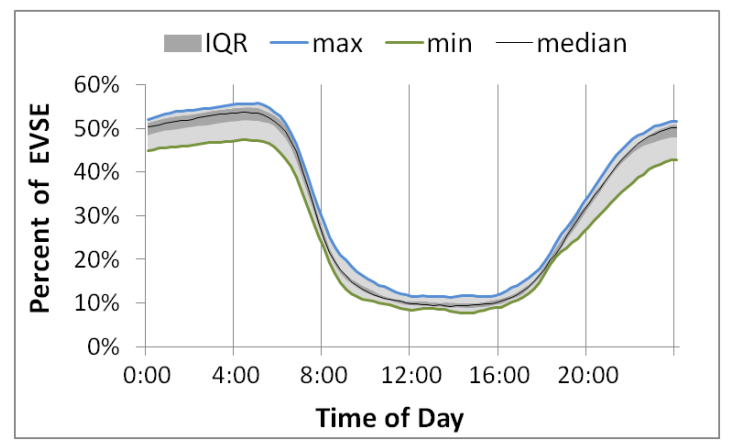

Figure 10: Time-of-day charging availability plot with median and inner quartile range.

Figure 10 shows that during the 3 -week period in October 2011, there tends to be more variation in 
charging availability during the night-time hours than during day-time hours. For example, at 03:00, the IQR is $3 \%$ and the overall range is $8 \%$. At 12:00 (noon), the IQR is about $1 \%$ and the overall range is $3 \%$. Further, between $22: 00$ and 06:00, the upper three quartiles are grouped closely together. This means that wide overall range of charging availability during these hours is due to a relatively small number of days with lower charging availability.

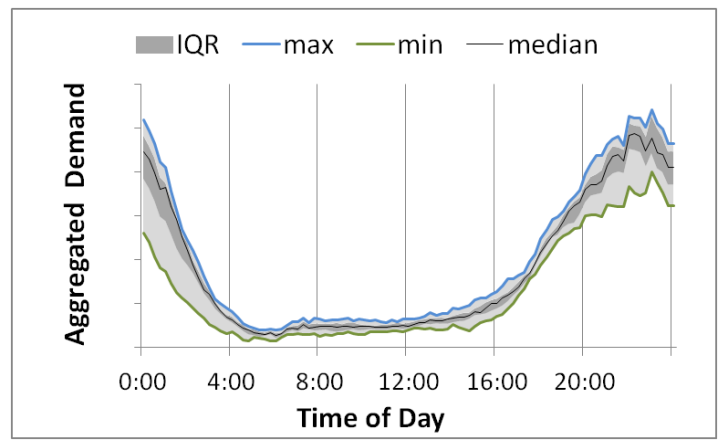

Figure 11: Time-of-day demand plot with median and inner quartile range.

Figure 11 shows that variation in charging demand is similar to variation in charging availability, with higher variability in the night-time hours.

\section{Results}

The data aggregation approach described in the preceding section was applied to a set of EV Project EVSE usage data. These data were collected from 2,704 residential EVSE between October 1 and December 31, 2011. The EVSE are located in private households owning Nissan LEAFs in each of the project regions.

\subsection{Charging Availability}

Weekday and weekend time-of-day charging availability plots were first created for all EVSE in the data set. These are shown in Figures 12 and 13.

In general, Figures 12 and 13 show that The EV Project participants tend to have their vehicles connected at home in the evening and late night hours. The percent of EVSE connected begins to increase after 16:00 and reaches a peak between 04:00 and 05:00 on both weekdays and weekend days. The slow but steady increase in the number of EVSE connected between midnight and 04:00 indicates that some participants plug in their vehicles in the early morning hours. Charging availability then begins to drop as vehicles are disconnected from EVSE in increasing numbers after about 05:00, presumably as individuals depart their homes for work or other daily activities. As few as $8 \%$ of residential EVSE have vehicles connected during the mid-day hours on weekdays. The minimum percent of EVSE connected on weekend days is higher at $18 \%$. Fewer EVSE are connected during the early mornings after midnight on Saturdays and Sundays than on weekday early mornings.

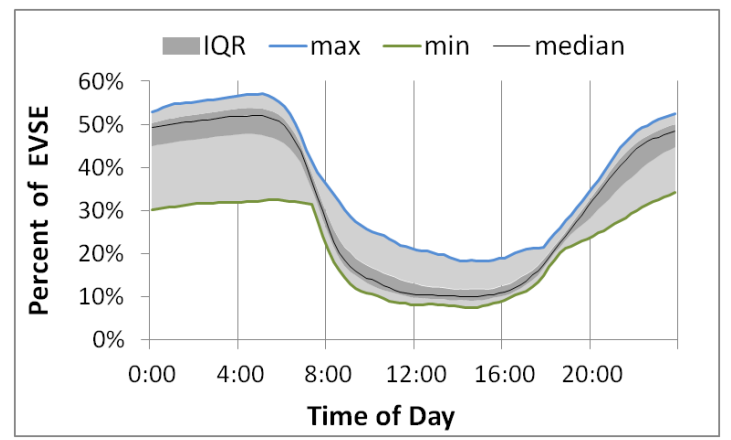

Figure 12: Weekday time-of-day charging availability for all EV Project regions.

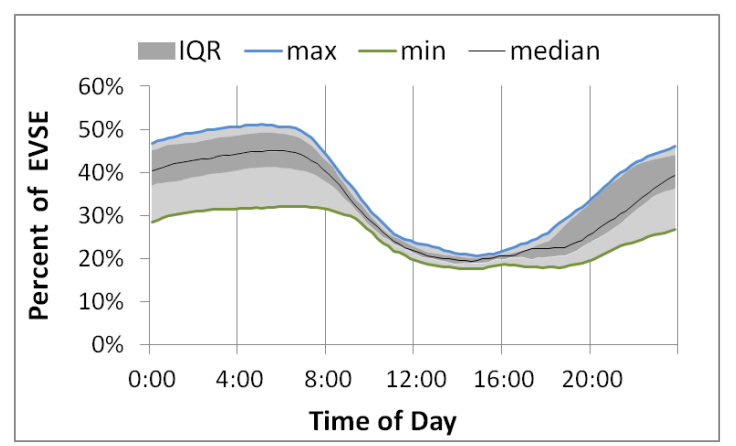

Figure 13: Weekend time-of-day charging availability for all EV Project regions

The range of variation in charging availability from calendar day to calendar day during the quarter is significant. In Figure 12, the time with highest variation on weekdays occurs between 0:00 and 05:00, when the percent of EVSE connected varies from about 30 to over $50 \%$. The range of the top three quartiles from midnight and 05:00 is about $9 \%$, but the range of the bottom quartile over the same time period is about $15 \%$. Also the range of the bottom three quartiles from 11:00 to $16: 00$ is about $4 \%$, whereas the range of the top quartile over the same time period is about $7 \%$. In both of these time periods, only one quarter of the data is responsible for about $60 \%$ of the spread between the maximum and the minimum.

Inspection of the charging availability curve for all of the fourth quarter (Q4) 2011 found that the increased size of the lower quartile between 0:00 
and 05:00 and the increased size of the upper quartile between 11:00 and 16:00 is due to a change in behavior on the days surrounding Thanksgiving and Christmas 2011. The weekdays from Monday, December 26 through Friday, December 30 saw fewer EVSE connected during the night and more EVSE connected during the day than during other weeks in the quarter. This trend is represented in Figure 12 by a decrease in the minimum charging availability (green line) between 20:00 and 06:00 and an increase in the maximum charging availability (blue line) from 09:00 to 18:00.

The IQR can be examined to focus on common behavior and ignore atypical behavior, such as that seen around the holidays. The tight IQR shown in Figure 12 indicates that common weekday charging availability has little variation from day to day. The largest IQR on weekdays or weekend days occurs on weekends between 20:00 and 06:00, indicating that this is the period of greatest variation in user "plugging-in" behavior from day to day.

Weekend charging availability in Figure 13 follows a pattern similar to behavior on weekdays around the holidays, in that the median charging availability is lower at night and higher during the day compared to most weekdays. On weekend days, there is very little variation across days between noon and 16:00 on weekends, when 18 to $23 \%$ of EVSE are connected.

Time-of-day charging availability plots also were generated for individual EV Project regions. Figures 14 and 15 show these plots for the Nashville region in Q4 2011.

With the exception of less smooth lines due to a smaller sample size, the patterns in these figures are similar to the patterns in the charging availability plots for all EV Project EVSE in the data set (Figures 12 and 13).

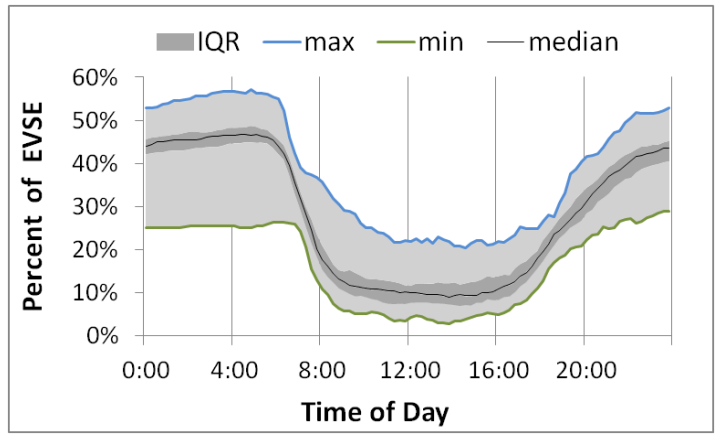

Figure 14: Weekday time-of-day charging availability for Nashville.

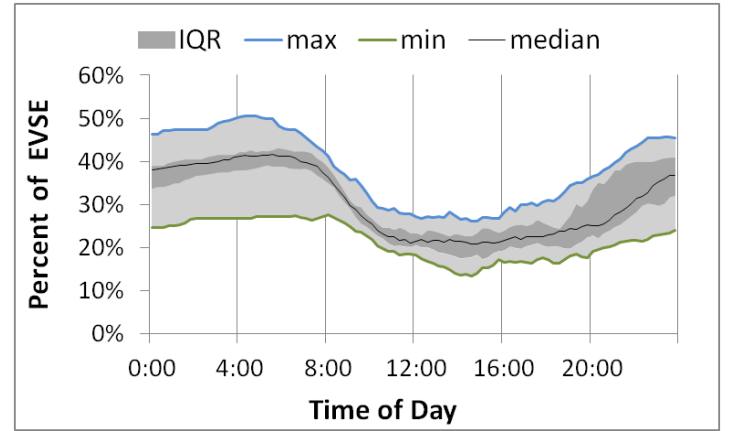

Figure 15: Weekend time-of-day charging availability for Nashville

Figures 16 and 17 show time-of-day charging availability for the San Francisco region in the Q4 2011.

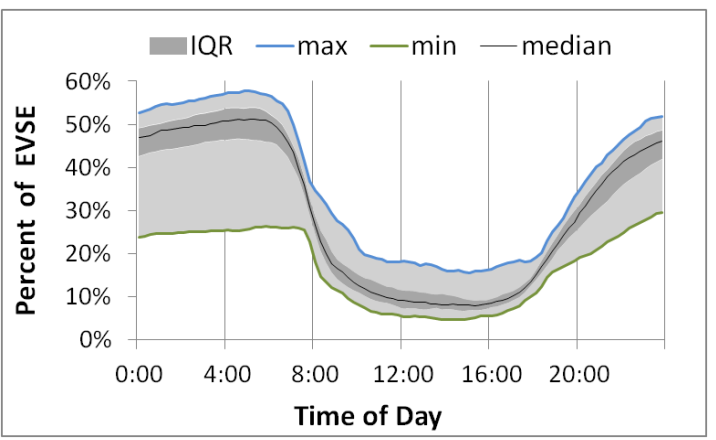

Figure 16: Weekday time-of-day charging availability for San Francisco.

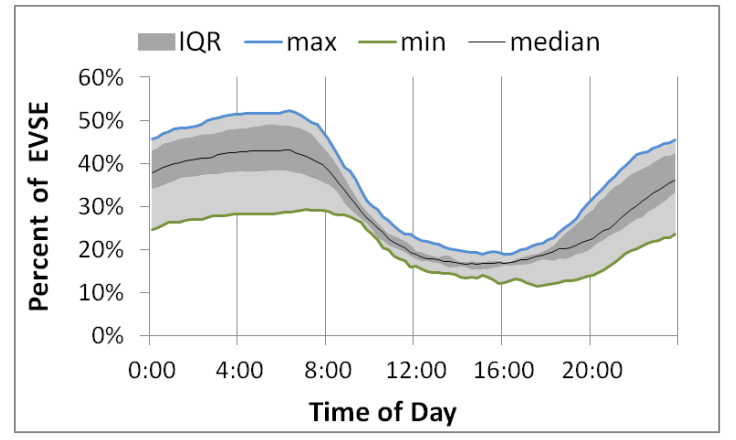

Figure 17: Weekend time-of-day charging availability for San Francisco

Again, these plots show similar patterns. This indicates that participants in the San Francisco region exhibited the same behavior as their counterparts in the Nashville region and as the overall project population, with respect to when they connect their vehicles to their residential EVSE.

\subsection{Charging Demand}

Time-of-day charging demand plots were generated from the data set for all EV Project regions in Q4 2011. The magnitude of the demand was normalized per EVSE by dividing the 
magnitude of the charging demand curve by the number of EVSE available for use on a given day and time. These plots are shown in Figures 19 and 20 .

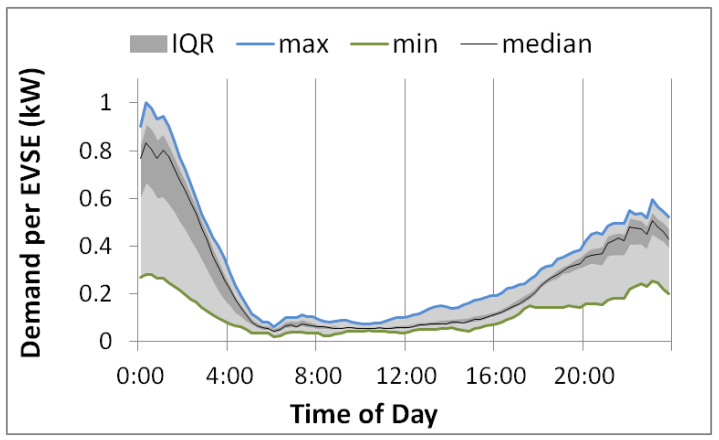

Figure 19: Weekday time-of-day charging demand for all EV Project regions.

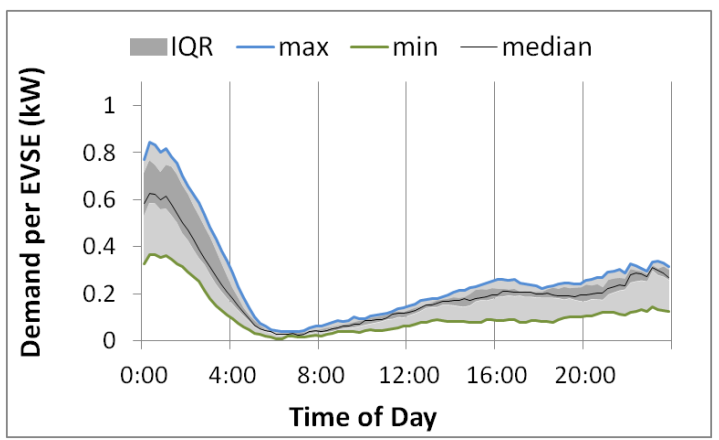

Figure 20: Weekend time-of-day charging demand for all EV Project regions.

On first glance, it may appear that the charging demand magnitude in these figures is too low. After all, a single Nissan LEAF draws about $3.3 \mathrm{~kW}$ during steady-state charging, yet the charging demand time-of-day plot never exceeds $1 \mathrm{~kW}$. Note, however, that the percent of EVSE connected to a vehicle never exceeds $60 \%$, as shown in Figure 12. Thus, the normalized charging demand per EVSE will never exceed $60 \%$ of the maximum possible demand for one vehicle. Furthermore, not all vehicles that are connected to EVSE are drawing power. At any given time, a fraction of the vehicles connected have full battery packs and have ceased drawing power from the EVSE. The charging demand plots show the resulting demand of EVSE with vehicles connected and drawing power, normalized with respect to all EVSE in the data set.

When comparing charging demand in Figures 19 and 20 to charging availability in Figures 12 and 13 , it is immediately apparent that demand is not proportional to the percent of EVSE connected to a vehicle. This occurs for two reasons. First, demand begins to fall off after about 01:00, even though charging availability remains high until about 6:00. Demand falls during this period as battery packs reach full charge and the vehicle control system stops power flow, even though the vehicle is still connected to the EVSE. This is consistent with analysis of individual charging events. For residential EVSE in all project regions, the average duration of time connected per charging event is 11.5 hours, whereas the average period of time when the vehicle draws power per charging event is 2.2 hours [5].

Second, charging availability steadily increases in the evening hours, whereas demand increases only slightly in the evening and then increases dramatically at midnight. This difference is due to user charge scheduling. The large spike in demand at midnight, as well as the small jumps on the hour between 20:00 and 01:00, is the result of numerous users programming their EVSE or vehicles to commence charging at these times.

As with charging availability, the minimum charging demand (green lines in Figures 19 and 20) is reduced considerably due to different user behavior around Thanksgiving and Christmas time. Otherwise, the upper three quartiles are fairly tightly grouped, indicating there is consistent demand for electricity from day to day in Q4, excluding the days around the holidays.

Demand on weekdays and weekend days drops to nearly $0 \mathrm{~kW}$ per EVSE between 05:00 and 06:00, even though charging availability does not begin to fall off until 06:00 or later. This indicates that the Nissan LEAFs being charged have sufficient time to fully charge during the night. Note that this is a function of the state of charge of the vehicles' batteries prior to charging, which is a function of how much the vehicles have been driven prior to charging. This topic will be studied in future works.

To investigate regional differences in demand, charging demand plots were generated for the Nashville EV Project region. These plots are shown in Figures 21 and 22. 


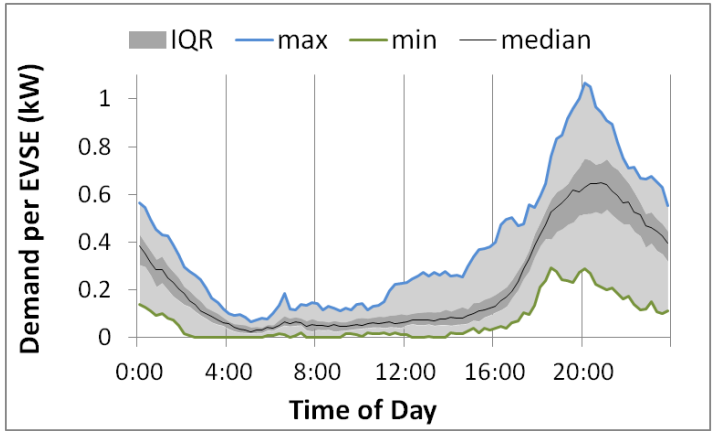

Figure 21: Weekday time-of-day charging demand for Nashville.

In Nashville, an increase in the weekday demand curve from 16:00 to $20: 00$ corresponds to the increase in the charging availability curve over the same time period shown in Figure 14. In this region, most users do not program their vehicles or EVSE to begin charging at a scheduled time. Instead, the vehicles begin to draw power from the EVSE immediately after they are plugged in. Because people arrive home or otherwise choose to plug in their vehicles at home at different times throughout the evening, charging demand increases gradually. This charging diversity leads to relatively low peak demand and smooth changes in demand.

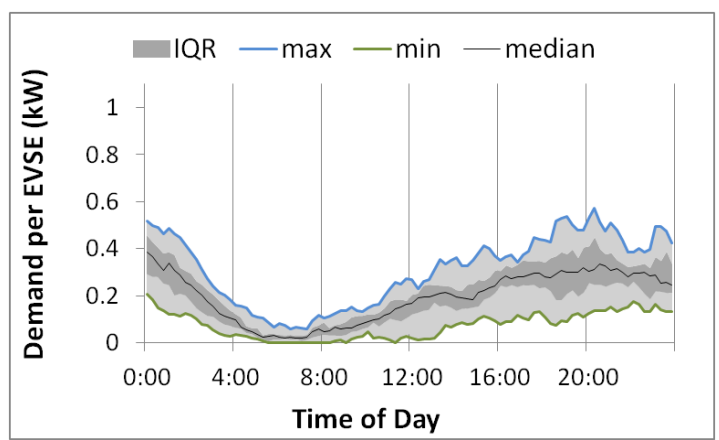

Figure 22: Weekend time-of-day charging demand for Nashville.

The weekend charging demand increases in Nashville on weekend days between 08:00 and 12:00 (Figure 22), despite a decrease in charging availability during this time (Figure 15). Demand increases as vehicles are connected to EVSE during this period and the vehicles begin to charge immediately. Charging availability decreases during this time because the number of vehicles being disconnected from EVSE is greater than the number of vehicles being connected. However, the vehicles being disconnected had already completed charging prior to the time they are unplugged; therefore, the disconnecting of vehicles does not reduce charging demand.
Charging demand plots also were generated for the San Francisco EV Project region. These plots are shown in Figures 23 and 24.

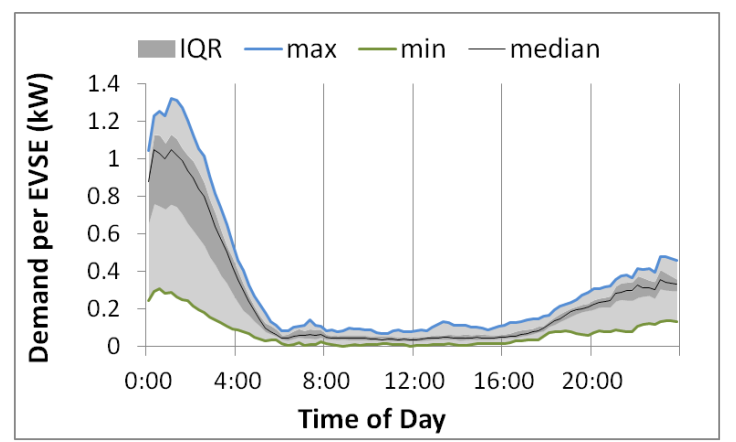

Figure 23: Weekday time-of-day charging demand for San Francisco.

In San Francisco, a large increase in demand occurs at 00:00 (midnight). This is depicted in Figures 23 and 24 by comparing the far right-hand side of each plot to the far left-hand side of the same plot.

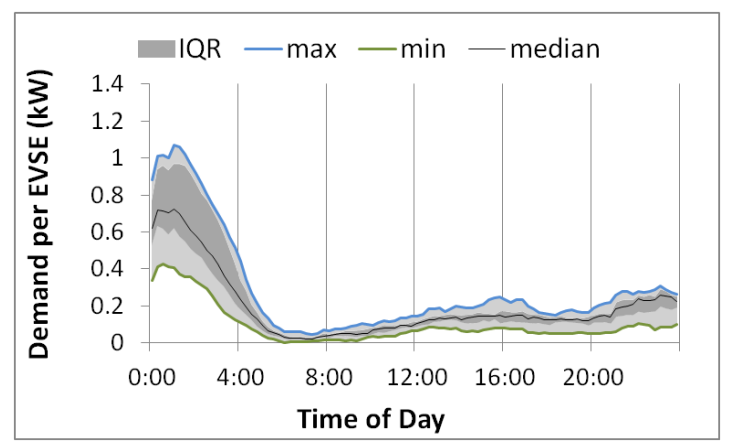

Figure 24: Weekend time-of-day charging demand for San Francisco.

Figures 25 and 26 show the same weekday and weekend charging demand for San Francisco, but with the time scale on the $\mathrm{x}$ axis shifted to the right by 16 hours to allow visualization of the increase in demand at midnight. 


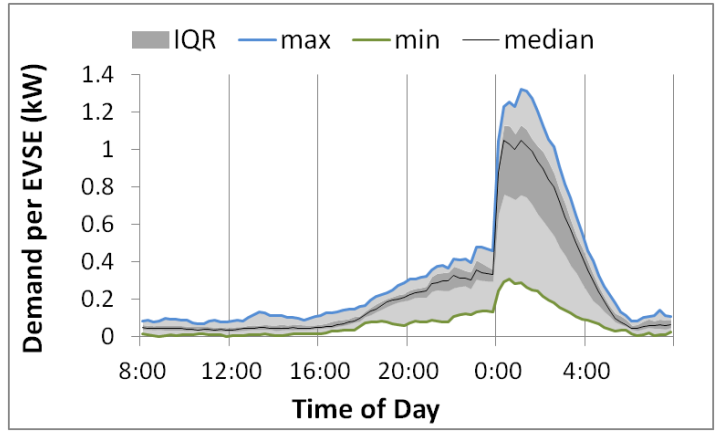

Figure 25: Weekday time-of-day charging demand for San Francisco with shifted time scale.

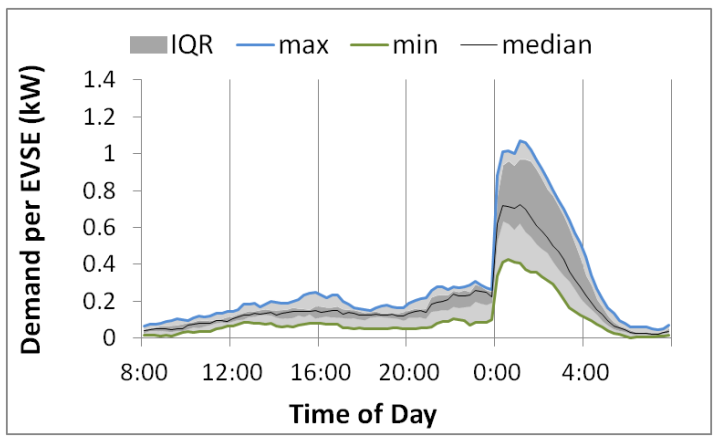

Figure 25: Weekend time-of-day charging demand for San Francisco with shifted time scale.

As mentioned previously, the midnight spike in demand is a result of a large number of users programming their EVSE or vehicles to begin charging at midnight.

Ninety percent of EVSE in the San Francisco region are located in the Pacific Gas \& Electric service territory. This electric utility offers its EV-owning customers an experimental residential time-of-use rates for "low emission vehicle refueling." In this rate structure, the cost per kilowatt-hour of electricity is reduced during off-peak hours. On weekdays, the off-peak period is from midnight to 07:00. Weekend off-peak hours start at 21:00 [6]. While it is not possible to determine which customers have signed up for these rates, it obvious from the plots that many EVSE users schedule the start of vehicle charging at midnight. It is assumed that this behavior is motivated by the desire to take advantage of the reduced electricity price.

The tendency for many EVSE users in the region to begin charging at midnight has consequences. First, the strong increase in charging availability from $16: 00$ to $22: 00$ is not accompanied by an equivalent increase in the demand curve. Instead, the demand curve has only a slight increase over this time period. This serves to reduce the demand on the electric grid during the afternoon and evening hours, which is typically the period of peak demand. Second, because many people schedule to begin charging immediately at 00:00, a nearly instantaneous spike in demand occurs. This large spike in demand may pose problems for low-voltage distribution systems.

Peak demand in San Francisco occurs at 01:00. This occurs because a relatively small number of EVSE users schedule charging to begin at this time. The demand from these EVSE augments the demand from EVSE whose vehicles began charging at 00:00 and are still charging.

Because there is less diversity when vehicles begin charging in San Francisco than in Nashville, the absolute peak in San Francisco is greater. San Francisco's weekday peak median demand is $1.05 \mathrm{~kW}$ per EVSE, compared to $0.65 \mathrm{~kW}$ in Nashville. It should be noted that the energy consumed per EVSE per day in these two regions is the same, making this comparison possible. These differences in peak demand occur because EV Project participants in San Francisco tend to program their EVSE or vehicles to start charging at a specific time, whereas participants in Nashville do not. It is assumed that this behavior is driven by the availability (or lack thereof) of reduced electricity price through time-of-use rates.

\section{Conclusion}

This paper summarizes early usage of EV Project residential EVSE in households with Nissan LEAFs, based on data collected during Q4 2011 from 2,704 EVSE. A method of data aggregation was developed to summarize EVSE usage by the means of two metrics: charging availability and charging demand. Charging availability was plotted relative to time of day and day of the week to show the range of percentage of EVSE connected to a vehicle over time. Charging demand was plotted to show the range of charging demand of the EVSE on the electric gird over time.

In general, residential EVSE charging availability is low during the day, steadily increases in the evening, and remains high at night. Charging availability, which is a function of when individuals connect their vehicles to their EVSE, is consistent across EV Project regions.

Day-to-day variation in charging availability and charging demand on weekdays is high during Q4 2011, because user behavior on the weekdays surrounding Thanksgiving and Christmas varies from the other weekdays in the quarter. On the 
weekdays surrounding the holidays, charging availability was low at night and high during the day, similar to weekend charging availability. To ignore the effect of the holidays and compare common weekday and weekend user behavior, the charging availability IQR was used. The IQR is highest on weekends between 20:00 and 06:00, indicating that this is the period of greatest variation in user "plugging-in" behavior from day to day, excluding days close to or on holidays.

When EVSE in all regions are examined in aggregate, demand peaks on weekdays and weekend days during the 00:00 hour. Weekday demand is lowest between 06:00 and 12:00, during which time it is nearly $0 \mathrm{~kW}$ per EVSE.

In order to identify regional differences in charging demand, EVSE usage in two individual EV Project regions was examined.

In Nashville, where EV Project participants do not have time-of-use electricity rates, demand increases each evening as charging availability increases, starting at about 16:00. Demand peaks in the 20:00 hour on weekdays.

In San Francisco, the majority of EV Project participants have the option of choosing a special time-of-use rate plan from their electric utility. In this region, demand spikes at 00:00, which is the beginning of the off-peak electricity rate period. Demand peaks at 01:00.

In both regions, demand on weekdays and weekend days drops to nearly $0 \mathrm{~kW}$ per EVSE between 05:00 and 06:00, even though charging availability does not begin to fall off until 06:00 or later. This suggests that the Nissan LEAFs being charged have sufficient time to fully charge during the night. Note that this is a function of how much the vehicles are driven prior to charging. This topic will be addressed in future works.

In San Francisco, financial incentive provided by time-of-use rates appears to successfully shift charging demand to off-peak hours. This may benefit the electric utility by preventing an increase in peak system demand. However, a large number of users in this region schedule charging to begin immediately at midnight, which is the beginning of the off-peak period. This low diversity in charging start time creates an unintended demand spike at the beginning of the off-peak period. This may pose a different set of problems to the electric utility.

\section{Acknowledgments}

Funding for The EV Project is provided in part by the U.S. Department of Energy's Vehicle Technologies Program through a grant from the American Reinvestment and Recovery Act.

\section{References}

[1] R. Liu, L. Dow, E. Liu, “A Survey of PEV Impacts on Electric Utilities," IEEE PES Innovative Smart Grid Technologies Conference, Anaheim, CA, January 2011

[2] M. Kintner-Meyer, K. Schneider, R. Pratt, "Impacts Assessment of PHEVs on Electric Utilities and Regional U.S. Power Grids, Part 1: Technical Analysis," PNNL SA53700, November 2007

[3] S. Hadley, A. Tsvetkova, "Potential Impacts of Plug-in Hybrid Electric Vehicles on Regional Power Generation," ORNL/TM2007/150, January 2008

[4] J. Smart, J. Davies, M. Shirk, C. Quinn, K. Kurani, "Electricity Demand of PHEVs Operated by Private Households and Commercial Fleets: Effects of Driving and Charging Behavior," EVS25, Shenzhen, China, Nov. 5-9, 2010

[5] "EV Project Electric Vehicle Charging Infrastructure Summary Report," October through December 2011, http://avt.inl.gov/ pdf/EVProj/EVProjInfrastructureQ42011.pdf

[6] http://www.pge.com/tariffs/tm2/pdf/ ELEC_SCHEDS_E-9, accessed January 2012.

\section{Authors}

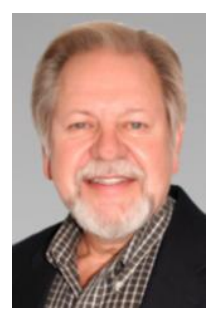

\section{Stephen Schey}

Director Stakeholder Services, ECOtality North America Mr. Schey has a B.S. in Mathematics from the U.S. Naval Academy and a M.S. in Mathematics from the U.S. Naval Postgraduate School. He has over 12 years of experience with EVs and related infrastructure. Formerly the GM EV1 Infrastructure Manager for Edison EV (a subsidiary of Southern California Edison), Schey was involved in the deployment of EV infrastructure in Phoenix and Tucson. Schey was also involved in the development and sales of fast charging equipment for industrial material handling equipment and ground support equipment for eTec under the Minit-Charger brand. In his current role, he is responsible for the planning phases of The EV Project, OEM integration, and project evaluation. He directs the electric utility 
relations group and leads the EVSE Infrastructure planning consulting efforts.

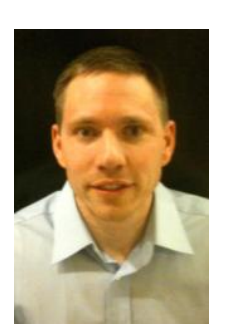

\section{Don Scoffield}

Mr. Scoffield is an engineer in the Energy Storage and Transportation Systems department at the Idaho National Laboratory.

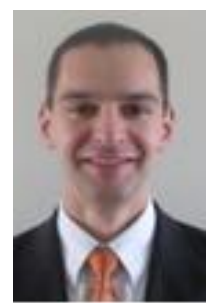

\section{John Smart}

Mr. Smart is an engineer in the Energy Storage and Transportation Systems department at the Idaho National Laboratory.

\section{Disclaimer}

References herein to any specific commercial product, process, or service by trade name, trademark, manufacturer, or otherwise, does not necessarily constitute or imply its endorsement, recommendation, or favoring by the U.S. Government, any agency thereof, or any company affiliated with the Idaho National Laboratory.

INL/CON-11- 22696 